\title{
Labor Market Volatility, Gender, and Trade Preferences
}

\author{
Ryan Brutger ${ }^{1 \star}$ (D) and Alexandra Guisinger ${ }^{2}$ (D) \\ ${ }^{1}$ Travers Department of Political Science, University of California, Berkeley, CA, USA and ${ }^{2}$ Department of \\ Political Science, Temple University, Philadelphia, PA, USA \\ ${ }^{\star}$ Corresponding author. Email: brutger@berkeley.edu
}

\begin{abstract}
What explains divides in the public's support for trade protection? Traditional economic arguments primarily focus on individuals' expectations for increased or decreased wages in the face of greater economic openness, yet studies testing such wage-based concerns identify a different divide as well: even after accounting for wage effects, women are typically more supportive of trade protection. We argue that trade-induced employment volatility and the resulting concerns for employment stability are overlooked factors that help explain the gender divide in attitudes. Due to both structural discrimination and societal norms, we theorize that working women are more responsive to the threat of trade-related employment instability than male counterparts. Using an experiment fielded on national samples in the USA and Canada, we find that most respondents have weak reactions to volatility, but volatility has a significant effect on women who are the most vulnerable to trade's disruptive effects - those working in import-competing industries and those with limited education.
\end{abstract}

Keywords: Trade attitudes; public opinion; labor volatility; gender; women; protectionism; trade protection

What explains divides in the public's support for trade protection? Traditional economic arguments have primarily focused on the wage effects of trade: due to skill level or sector of employment, some individuals may expect trade to increase demand for their labor and thus increase their wages while others fear that increased openness to international markets brings increased competition and lower wages. Yet, numerous studies analyzing the strength of such concerns have identified a different divide. In both developed and developing countries, women are on average more supportive of trade protection than men even after accounting for skill levels and sector of employment (Beaulieu and Napier 2008; Guisinger 2009, 2017; 
Hiscox and Burgoon 2004; Mayda and Rodrik 2005). To explain this divide, some scholars have turned to consumption patterns (Hall, Kao, and Nelson 1998) or noneconomic rationales such as sociotropic factors; national pride, isolationism, and chauvinism; values and ideology; risk orientation; knowledge gaps; and surveytaking behavior (Ehrlich and Maestas 2010; Hiscox and Burgoon 2004; Kleinberg and Fordham 2011; Lee 2011; Mansfield, Mutz, and Silver 2015; Tomiura et al. 2016). We argue instead that employment stability is an overlooked economic goal, and differential expectations of the cost of instability help to explain the persistent gender gap in support for trade protection.

Guisinger $(2016,2017)$ argued that higher support for trade protection among women reflects a rational response to concerns about employment volatility that accompanies trade liberalization. A corollary to orthodox trade theory's expectation that increased liberalization generates increased growth is that increased liberalization also increases economic uncertainty, volatility, and risk (Giovanni and Levchenko 2009; Kose, Prasad, and Terrones 2006; Ramey and Ramey 1994). The Bhagwati-Dehejia hypothesis predicts increased employment turnover in highly open countries; and empirically, policies resulting in trade liberalization appear linked with short-term employment adjustments and long-term increased volatility of employment (Beaulieu and Dehejia 2007). Because of historical and current employment practices, where women and minorities face disadvantages in recruitment processes (Padavic, Reskin et al. 2002) and retention practices (Diebold, Neumark, and Polsky 1997; Hall, Gordon, and Holt 1972; Ureta 1992) in the USA, Canada, and other similar developed countries, these employment adjustments disproportionately affect women (Diebold, Neumark, and Polsky 1997; Hall, Gordon, and Holt 1972; Sheeran 1975; Ureta 1992). Recent studies (Kushi and McManus 2018; Women's Budget Group 2018) have shown that in countries with greater gender discrimination, women are more likely than men to be exposed to the downside risks associated with trade liberalization and other economic shocks.

Furthermore, employment adjustment costs appear to weigh more heavily on women. Women generally bear a greater burden for homelife responsibilities (Ferrant, Pesando, and Nowacka 2014; Presser 1994), place a higher value on flexible work schedules, and prioritize other economic goals such as geographic stability and family-friendly work hours (Darian 1975; Gidengil et al. 2003; Glass and Camarigg 1992; Mansfield, Mutz, and Silver 2015; Presser 1994). Such gender-based differences in workplace treatment, work-life balance, and employment goals - and their influence on individuals' sensitivity to employment volatility - may provide an explanation for the persistence of the gender gap in attitudes toward trade, even after considering the known differences in sector and skill level characteristics.

Our argument assumes that the average working woman is more responsive to the threat of trade-related employment instability than her male counterpart and that this, in turn, influences policy preferences. To assess the potential impact of these concerns, we fielded a survey experiment on national samples in the USA and Canada that is designed to test how trade volatility affects attitudes toward trade and the mechanisms through which volatility shapes trade preferences. The experiment exposes half the respondents to a Volatility treatment, which describes how trade induces labor volatility, including both job gains and job losses. The study then 
asks about respondents' trade preferences, and also their perceptions of trade-related employment concerns, including the likelihood of losing one's job, the likelihood of gaining a new job, expected unemployment duration, and wage expectations. Analyzing these mechanisms allows us to test whether men and women react to trade-induced volatility in different ways, and whether such differences in employment concerns can explain the gender gap in trade attitudes. In our preregistered analysis, we find that our volatility treatment has a relatively weak effect on average, but that the effect is stronger for women who are most vulnerable to trade, especially those working in import-competing industries and without a college education.

In testing the effect of volatility on trade attitudes, we recognize that employment vulnerability concerns are both linked to and separate from wage-based concerns. If wages are the primary factor shaping preferences, then a treatment priming volatility - which should not have an independent effect on average wages - rather than wages should not substantially influence preferences for trade. Whereas, if volatility is a significant factor, we should see an effect on mechanisms linking volatility concerns to trade policy preferences (e.g. job security, job prospects, unemployment duration) and in the trade policy preferences themselves. Specifically, we would expect that the treatment and control groups should differ in the overall population, even as we predict heterogeneity based on certain characteristics. As employment provides the starting point for these economic characterizations and concerns, these differences should be most apparent among those currently in the workforce and particularly among tradeaffected workers, as discussed in section 4 of the appendix.

H1a: Those in the treatment group should rate more negatively the impact of increasing trade on their employment prospects than those in the control group.

H1b: Those in the treatment group should be more likely to state that they will lose their job because of increasing trade, will be less likely to state that they will gain a job, and will expect longer unemployment durations.

H1c: Those in the treatment group should be less positive about the benefits of increasing trade for themselves and others.

H1d: Those in the treatment group should be less supportive/more opposed to increased trade.

Analysis of average treatment effects for the aggregate sample can provide support for the general proposition that volatility and employment vulnerability influence preferences but, as noted, may gloss over important gender differences arising from different treatment in the workplace, homelife burdens, and preferences over employment goals. Combined, these conditions and attitudes should serve to increase women's average vulnerability to economic volatility.

Although we expect volatility to broadly affect trade attitudes, we specifically expect to see a stronger negative response to the volatility treatment among women than men. Given structural discrimination and women's greater concerns for job flexibility and other factors, we expect women to react more strongly to the treatment than 
men. Additionally, if men are less affected by employment constraints and structural disadvantages, they may view the potential upside of increased trade more optimistically than women, even when provided the volatility treatment.

H2a: Treatment effects should be stronger for women than men when testing H1a-H1d.

Furthermore, we should observe differences between the working and nonworking populations. Testing the differences between working and nonworking women provides a measure of the importance of employment-based concerns as a source of the gender gap in trade preferences. Some scholars (e.g. Borghans et al. 2009 and Charness and Gneezy 2012) have suggested that women are simply more risk averse on average than men. If this is the case, we should observe no difference between working women and nonworking women, but if specific employment concerns drive responses, we should also observe a difference in response to the volatility treatment between working and nonworking women. ${ }^{1}$

H2b: Treatment effects should be stronger for working women than non-working women when testing H2a.

Finally, we expect that those individuals who believe they are most vulnerable to losing their job, those who are least likely to be able to move for a new job, and those who place greater importance on having a flexible schedule will perceive trade-induced labor volatility as the most harmful. Additionally, we expect these traits to be more prevalent among women. To test this, we include three pretreatment questions in our survey, which assess respondents' relative likelihood of losing their job if their firm were in financial difficulties, respondents' willingness to move for a job, and respondents' prioritization of a flexible job schedule. In the main text, we discuss the analysis of the first two mechanisms and in section 3 of the appendix, we also present a more in-depth analysis of the (1) structural and workrelated aspects of gender discrimination, (2) uneven unpaid work burdens and family responsibilities, and (3) differing preferences for men and women and how they shape the effects of trade-induced labor volatility.

H3a: Treatment effects should be stronger for those who believe they are at higher risk of losing their job when testing H1a-H1d.

H3b: Treatment effects should be stronger for those who are less willing to move to take a new job when testing H1a-H1d.

\section{Research design}

To test our hypotheses, we fielded a survey experiment on national samples of approximately 3,000 respondents each in the USA and Canada, using Dynata.

\footnotetext{
${ }^{1}$ We also consider the effects of volatility based on skill level and sectoral affiliation, which we have discussed in section 4 of the appendix.
} 
The study recruits participants stratified based on census targets for gender, age, household income, and education. ${ }^{2}$

The study was designed to test how trade volatility affects attitudes toward trade and the mechanisms that contribute to the persistent gender gap in support for trade protection. To do so, half the respondents were initially assigned to our Volatility treatment, which stated "Trade between countries leads to both [new jobs and layoffs OR layoffs and new jobs]. As the U.S. has increased trade, it has experienced increased [job gains and job loses OR job loses and job gains], in a process referred to as labor volatility." 3 The treatment was designed and pretested to ensure that it was not presenting a one-sided view of volatility and was consistent with the concept's application in trade politics, which focuses on trade-induced volatility in the labor market. Next, all respondents were asked to think "about the increasing amount of trade between the U.S. and other countries" and then presented with a series of questions that asked about their attitudes toward trade, the consequences of trade, and perceptions of employment prospects and the labor market. ${ }^{4}$

Our study was fielded in July 2020, at a time when the global spread of COVID-19 had dramatically reshaped employment and employment concerns. Historically, economic shocks have made trade issues more politicized and more salient for the public, suggesting that our study was fielded at a time when the salience of trade politics is especially high. However, this new source of volatility creates an empirical issue since the effects of the pandemic have been unevenly distributed across sectors and certain segments of the population. In response, we include a pretreatment question that asks respondents whether jobs in their employment sector are at immediate risk due to COVID-19, which allows us to analyze whether increased perceptions of coronavirus-induced employment risks interact with trade-induced labor volatility to strengthen protectionist sentiments. ${ }^{5}$

For context, Figure 1 displays the proportion of control group respondents supporting trade (left) and the proportion who believe that trade enhances employment prospects (right). Within the control group, $64 \%$ of men support trade and only $52 \%$ of women do so $(p<0.01)$, and men in the sample are 9 percentage points more likely than women to believe that trade enhances their employment opportunities $(p<0.01)$. These measures confirm that our sample has the expected gender divide in initial attitudes toward trade.

\section{Results}

We begin our analysis by testing H1a through H1d, which states that the volatility treatment should negatively affect perceptions of employment prospects and attitudes toward trade. Since our main dependent variables of interest focus on respondents' employment prospects, we begin our analysis by subsetting our sample

\footnotetext{
${ }^{2}$ For the Canadian sample, the education target was not included due to recruitment feasibility.

${ }^{3}$ For Canadian respondents, the prompt says Canada instead of "the U.S." in this and in the subsequent examples.

${ }^{4} \mathrm{~A}$ complete description of the survey instrument is provided in section 2 of the appendix.

${ }^{5}$ In the appendix, section 6, we also discuss and test the effects of individual job loss due to coronavirus.
} 


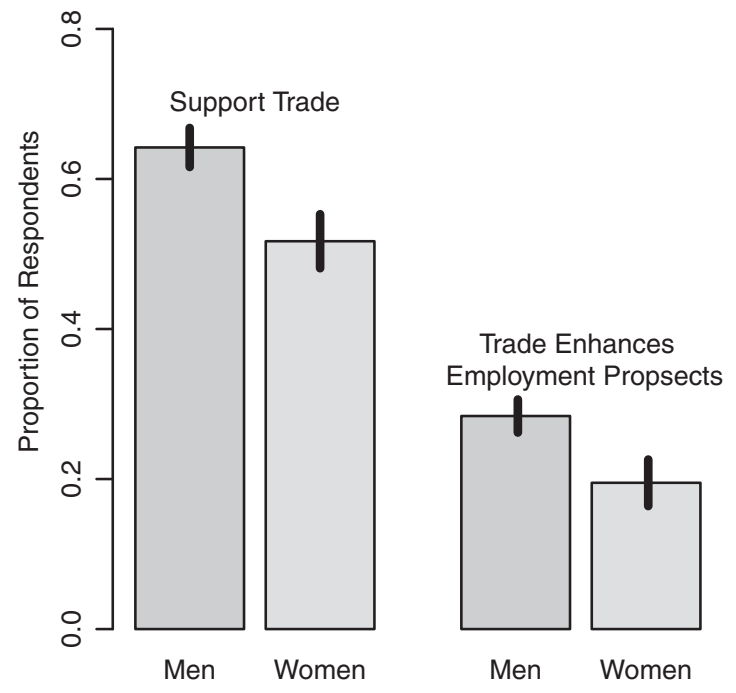

Figure 1

Baseline Trade Attitudes.

NOTES: Figure 1 displays the proportion of respondents supporting trade and the proportion who believe trade enhances their employment prospects in the baseline control condition for men and women, with the $95 \%$ confidence interval for each calculated using OLS.

to those individuals who are currently in the workforce. ${ }^{6}$ For H1a, respondents were asked "what impact do you believe increasing trade has had on your employment prospects?" Respondents were asked to select whether trade had enhanced, hurt, or had no change in their employment opportunities. For H1b, respondents were asked "How likely are you to lose your job because of increasing trade?" as well as "How likely are you to take a new job because of increasing trade?" with response options ranging from "extremely likely" to "extremely unlikely" on a five-point scale. To further probe the mechanisms of how labor volatility shapes attitudes toward trade, we also asked respondents to assess "If you were to lose your job in the next year, how many months do you think it would take you to find a new job at a similar or better income?"

Moving to the effects of our treatment on the perceived benefits of trade (H1c), we asked our respondents to assess "How good or bad has the United States' increasing trade been for each of the following?" with an evaluation given for themselves, their region, and their country and responses ranging from "very good" to "very bad." We also asked "Do you favor or oppose the U.S. negotiating more trade agreements with the goal of increasing trade?" which we use to test H1d. The results of our tests are displayed in Table 1, which displays the average treatment effects for respondents in the workforce, testing hypotheses H1a through H1d.

\footnotetext{
${ }^{6} \mathrm{We}$ measure whether a respondent is currently in the workforce using an adaptation of a standard workforce question displayed in section 2 of the appendix, where individuals are counted in the workforce if they are currently working full or part time.
} 
Table 1

Volatility's Effects among Working Respondents

\begin{tabular}{|c|c|c|c|c|c|c|c|c|}
\hline & \multicolumn{8}{|c|}{ Dependent Variable } \\
\hline & Employment & Lose Job & New Job & Job Search Time & Self & Region & Country & Trade Support \\
\hline & (1) & $(2)$ & (3) & (4) & (5) & (6) & (7) & (8) \\
\hline Volatility & $(0.023)$ & $(0.049)$ & $(0.047)$ & $(0.144)$ & $(0.032)$ & $(0.034)$ & $(0.038)$ & $(0.035)$ \\
\hline Constant & $2.176^{\star \star \star}$ & $2.405^{\star \star \star}$ & $2.559^{\star \star \star}$ & $5.816^{\star \star \star}$ & $3.146^{\star \star \star}$ & $3.237^{\star \star *}$ & $3.325^{\star \star *}$ & $3.693^{\star \star \star}$ \\
\hline Observations & 2,851 & 2,850 & 2,847 & 2,841 & 2,851 & 2,849 & 2,850 & 2,849 \\
\hline
\end{tabular}

NOTES: Sample is working respondents. ${ }^{*} p<0.1 ;{ }^{* *} p<0.05$; ${ }^{* * *} p<0.01$. Higher values for the dependent variables are associated with (1) enhanced employment opportunities, (2) greater likelihood of losing a job, (3) greater likelihood of finding a new job, (4) longer job search time, beliefs that trade is (5) good for the respondent, (6) good for the region, (7) good for the country, and (8) higher levels of support for trade. 
The average effects of the volatility treatment were small, inconsistent, and not significant for most measures. Respondents who received the treatment did not meaningfully differ in their answers concerning trade's overall effect on their employment prospects (enhance, hurt, or no change), but did show a small increase in the expected likelihood of both gaining a new job and losing their current job, and a small decrease in expected job search time.

We next turn to our analysis of how gender shapes attitudes toward trade and how gender interacts with our volatility treatment. First, we test H2a, which states that, among individuals in the workforce, our treatment effects should be stronger for women than men. To test this hypothesis, we replicate our earlier analysis, adding an interaction with whether the respondent identified as a woman.

We expect that the volatility treatment will have a larger negative effect on women's perception of trade's effect on their job prospects, both generally ("Employment") and specifically in terms of expectations for losing a job ("Lose Job"), gaining a job ("New Job"), and unemployment duration ("Job Search Time"). We also expect that the treatment will manifest in women having more negative views than men about the benefits of trade to themselves and others and lower their support for trade.

Our findings offer weak evidence for $\mathrm{H} 2$. For almost all measures, working women express more negative employment prospects than men, as shown in Table 2, but the volatility treatment has a very limited effect on the sample of working men and women. There were two effects that come close to traditional levels of significance for men. Volatility increases men's expectations (relative to untreated men) of gaining a new job ( $p=0.07)$, in contrast to the negative sign for volatility's effect on women's perceptions (relative to untreated women). Men who received the volatility treatment were also more likely to say that trade benefited themselves ("Self" $p=0.06$ ), but these findings were specific to men since in both cases the interaction with women negated the positive shift due to the treatment. The only significant effect among working women was that women who received the volatility treatment were less positive about the benefits of trade for the country as a whole $(p=0.06)$ than untreated women.

When the analysis takes into account not only gender, but also trade vulnerability in the form of low skill (no college degree) or employment in an import-competing industry, we find evidence of volatility's differential effects on women's trade support. Among working respondents with no college degree (Appendix, Table 17), the volatility treatment lowers support for trade among women $(-0.27, p=0.04)$, though volatility did not have an effect on men without a college degree. The results are stronger among respondents working in import-competing industries (Appendix, Table 14), for whom the volatility treatment strongly decreased women's support for trade compared to untreated women $(-0.33, p=0.02)$, even while volatility had no effect on men working in import-competing industries. In substantive terms, the percent of women supporting trade in import-competing industries in the control condition was $61 \%$, but in the volatility treatment, only $49 \%$ supported trade, resulting in a 12 percentage point drop in trade support $(p=0.03)$. Although the aggregate treatment effects were weak, the evidence shows that volatility has a significant effect on women who are the most vulnerable to trade's disruptive effects - those working in import-competing industries and those with limited education. 
Table 2

Volatility's Effects on Women and Men among Working Respondents

\begin{tabular}{|c|c|c|c|c|c|c|c|c|}
\hline & \multicolumn{8}{|c|}{ Dependent Variable } \\
\hline & Employment & Lose Job & New Job & Job Search Time & Self & Region & Country & Trade Support \\
\hline & (1) & (2) & (3) & (4) & (5) & (6) & (7) & (8) \\
\hline \multirow[t]{2}{*}{ Volatility } & 0.033 & $0.120^{\star}$ & $0.115^{*}$ & -0.214 & $0.081^{*}$ & 0.001 & 0.040 & -0.001 \\
\hline & $(0.032)$ & $(0.067)$ & $(0.064)$ & $(0.200)$ & $(0.044)$ & $(0.047)$ & $(0.052)$ & $(0.048)$ \\
\hline \multirow[t]{2}{*}{ Women } & $-0.135^{\star \star \star}$ & -0.056 & $-0.162^{\star \star}$ & 0.153 & $-0.212^{\star \star \star}$ & $-0.213^{\star \star \star}$ & $-0.215^{\star \star \star}$ & $-0.283^{\star \star \star}$ \\
\hline & $(0.032)$ & $(0.068)$ & $(0.065)$ & $(0.201)$ & $(0.044)$ & $(0.047)$ & $(0.052)$ & $(0.048)$ \\
\hline \multirow[t]{2}{*}{ Volatility:women } & -0.028 & -0.084 & -0.048 & -0.130 & -0.100 & -0.082 & $-0.139^{\star}$ & -0.054 \\
\hline & $(0.046)$ & $(0.097)$ & $(0.093)$ & $(0.289)$ & $(0.063)$ & $(0.068)$ & $(0.075)$ & $(0.069)$ \\
\hline \multirow[t]{2}{*}{ Constant } & $2.241^{\star \star \star}$ & $2.432^{\star \star \star}$ & $2.637^{\star \star \star}$ & $5.742^{\star \star \star}$ & $3.249^{\star \star \star}$ & $3.340^{\star \star \star}$ & $3.430^{\star \star \star}$ & $3.830^{\star \star \star}$ \\
\hline & $(0.022)$ & $(0.047)$ & $(0.045)$ & $(0.140)$ & $(0.031)$ & $(0.033)$ & $(0.036)$ & $(0.034)$ \\
\hline Observations & 2,851 & 2,850 & 2,847 & 2,841 & 2,851 & 2,849 & 2,850 & 2,849 \\
\hline \multicolumn{9}{|c|}{$\begin{array}{l}\text { NOTES: Sample is working respondents. }{ }^{*} p<0.1 ;{ }^{* *} p<0.05 ;{ }^{* *} p<0.01 \text {. Higher values for the dependent variables are associated with (1) enhanced employment opportunities, (2) greate } \\
\text { likelihood of losing a job, (3) greater likelihood of finding a new job, (4) longer job search time, beliefs that trade is (5) good for the respondent, (6) good for the region, ( } 7 \text { ) good for th } \\
\text { country, and (8) higher levels of support for trade. }\end{array}$} \\
\hline
\end{tabular}


We also expect labor volatility to be perceived as more disruptive to those who have less job security (H3a) and those who are less likely to be willing to move to find a new job (H3b). In section 3 of the appendix, we discuss the results with the addition of interaction terms between the treatment and our job security and willingness-to-move measures, in addition to employment goals, homelife burdens, earning responsibility, and the nature of full versus part-time work. Overall, we do not find strong evidence that respondents' provider role, their unpaid work responsibilities, or the nature of their participation in the workforce play a major role in shaping the effect of volatility on trade attitudes. We do find that those with higher job risk were significantly more likely to hold positive views on trade's effect on employment prospects, trade's benefits for self and country, and toward trade agreements. Interestingly, the volatility treatment has a positive main effect on respondent's employment prospects, as shown in the Appendix, Table $3(0.15, p=0.03)$, but the interaction between volatility and job risk was negative $(-0.04, p=0.04)$, which is consistent with our expectations.

Up until now, we have exclusively examined the effects of the volatility treatment on members of the workforce. We now test $\mathrm{H} 2 \mathrm{~b}$, which predicts stronger treatment effects among women in the workforce than women outside of the workforce. With a few exceptions, the treatment effects are relatively small and not significant. However, in line with the initial expectations of the paper, the volatility treatment decreases support for trade for all women, as shown in Table $3(-0.12, p<0.01)$. While the interaction term suggests that the treatment had a less negative effect on working women, the difference is not significant. In contrast, the treatment more clearly generated distinct responses according to men's workforce participation. Table 13 of the appendix shows that the volatility treatment had a positive effect on working men's employment prospects, but not men outside of the workforce.

The appendix also provides an analysis of the influence of COVID-19 employment risk on opinions about trade. We find that individuals who believe their sector is at risk of losing jobs due to COVID-19 are more likely to support trade and believe it is beneficial to their country, region, and themselves, as shown in Table 22 of the appendix. The volatility treatment has a positive interaction with those who perceive themselves at high unemployment risk due to COVID-19, resulting in them being somewhat more positive about the benefits of trade for themselves, their region, and country.

We also examine which employment concerns are most influential in shaping support for trade among those in the workforce. To do so, we employ mediation analysis (Tingley et al. 2014), testing the mediation effects of beliefs about employment prospects, expected job search time, likelihood of losing a job, likelihood of taking a new job, and wages, as shown in section 7 of the appendix. Consistent with the findings from Table 1, we did not find that any of the mediators had a strong effect.

We also included a manipulation check, as shown in section 2 of the appendix. Importantly, we did not find that gender was correlated with successfully answering the manipulation check. Analysis comparing only those who passed the manipulation check against the control group is displayed in Tables 24 and 25 of the appendix. 
Table 3

Volatility's Effects on Working and NonWorking Women

\begin{tabular}{|c|c|c|c|c|c|c|c|c|}
\hline & \multicolumn{8}{|c|}{ Dependent Variable } \\
\hline & Employment & Lose Job & New Job & Job Search Time & Self & Region & Country & Trade Support \\
\hline & (1) & (2) & (3) & (4) & (5) & (6) & (7) & (8) \\
\hline Volatility & $(0.029)$ & $(0.056)$ & $(0.056)$ & $(0.202)$ & $(0.034)$ & $(0.041)$ & $(0.047)$ & $(0.045)$ \\
\hline Working & $0.108^{\star \star \star}$ & 0.021 & 0.053 & $-1.339^{\star \star \star}$ & 0.042 & $0.111^{\star \star \star}$ & $0.179^{\star \star \star}$ & 0.033 \\
\hline \multirow[t]{2}{*}{ Volatility:working } & 0.010 & 0.009 & 0.047 & -0.239 & 0.028 & -0.021 & -0.099 & 0.066 \\
\hline & $(0.043)$ & $(0.083)$ & $(0.083)$ & $(0.301)$ & $(0.050)$ & $(0.060)$ & $(0.070)$ & $(0.067)$ \\
\hline \multirow[t]{2}{*}{ Constant } & $1.999^{\star \star \star}$ & $2.355^{\star \star \star}$ & $2.423^{\star \star \star}$ & $7.234^{\star \star \star}$ & $2.996^{\star \star \star}$ & $3.017^{\star \star \star}$ & $3.036^{\star \star *}$ & $3.515^{\star \star \star}$ \\
\hline & $(0.021)$ & $(0.040)$ & $(0.041)$ & $(0.146)$ & $(0.024)$ & $(0.029)$ & $(0.034)$ & $(0.033)$ \\
\hline Observations & 2,999 & 2,998 & 2,995 & 2,990 & 2,998 & 2,997 & 2,997 & 2,998 \\
\hline
\end{tabular}

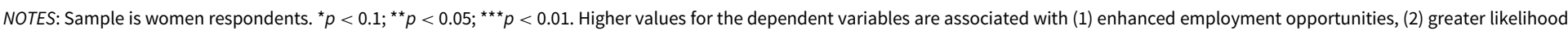

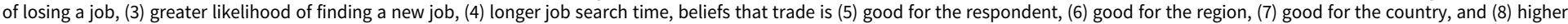
levels of support for trade. 


\section{Conclusion}

We sought to test whether the gender gap in trade support arose from differing evaluations of the costs and benefits from increased employment volatility generated by trade. We argued that due to structural discrimination and societal norms, women are more vulnerable to the risks of employment volatility. On average, women face more challenges in the employment marketplace and also have more constraints from nonemployment demands that would make them more concerned about the downsides of trade-induced employment volatility than men.

Using survey experiments fielded in the USA and Canada, our data confirmed the expected gender divide when it comes to support for trade and employment concerns about trade. In studying the gender divide for trade attitudes, we seriously considered how men's and women's different employment priorities and roles in the economy, such as differences in willingness to move for a new job and one's role as a caregiver, shaped attitudes toward trade and responses to employment volatility. While we found some interesting results, such as the finding that individuals who are more willing to move for a job believe volatility reduces their expected job search time compared to those who are less willing to move, the results provided little evidence that variation in individual employment priorities or family roles altered how employment volatility shaped attitudes toward trade.

The paper's main analysis focused on analyzing whether volatility is the source of the gender divide, but our results were inconsistent. For the respondents most vulnerable to the negative effects of trade - those without a college education or those in import-competing industries - the volatility treatment led women to hold more negative attitudes toward trade, even though men in these groups did not respond to the treatment. These results support the theory that trade-induced employment volatility is perceived differently by men and women, but the differences primarily manifest among those who are most vulnerable to losing their job due to trade. By contrast, the results for the aggregate sample were much weaker, which suggests that the gender divide on trade attitudes is driven by many factors beyond employment volatility and that understanding these mechanisms continues to be a valuable pursuit for future research.

Supplementary Material. To view supplementary material for this article, please visit https://doi.org/10. 1017/XPS.2021.9.

Data Availability. The data, code, and any additional materials required to replicate all analyses in this article are available at the Journal of Experimental Political Science Dataverse within the Harvard Dataverse Network, at: doi:10.7910/DVN/AWRD8O (Brutger and Guisinger 2021).

Conflicts of Interest. The authors do not have any conflict of interests to report in relation to this manuscript and study.

\section{References}

Beaulieu, Eugene and Michael Napier. 2008. Why are Women more Protectionist than Men? Unpublished manuscript. Department of Economics, University of Calgary.

Beaulieu, Eugene and Vivek H. Dehejia. 2007. International Trade, Labor Turnover, and The Wage Premium: Testing the Bhagwati-Dehejia Hypothesis for Canada. In Trade, Globalization and Poverty. Routledge. 
Borghans, Lex, James J. Heckman, Bart H. H. Golsteyn, and Huub Meijers. 2009. Gender Differences in Risk Aversion and Ambiguity Aversion. Journal of the European Economic Association 7(2-3): 649-58.

Brutger, Ryan and Alexandra Guisinger. 2021. Replication Data for: Labor Market Volatility, Gender, and Trade Preferences. Harvard Dataverse, doi: 10.7910/DVN/AWRD8O.

Charness, Gary and Uri Gneezy. 2012. Strong Evidence for Gender Differences in Risk Taking. Journal of Economic Behavior \& Organization 83(1): 50-8.

Darian, Jean C. 1975. Convenience of Work and the Job Constraint of Children. Demography 12(2): 245-58.

Diebold, Francis X., David Neumark, and Daniel Polsky. 1997. Job Stability in the United States. Journal of Labor Economics 15(2): 206-33.

Ehrlich, Sean and Cherie Maestas. 2010. Risk Orientation, Risk Exposure, and Policy Opinions: The Case of Free Trade. Political Psychology 31(5): 657-84.

Ferrant, Gaëlle, Luca Maria Pesando, and Keiko Nowacka. 2014. Unpaid Care Work: The Missing Link in the Analysis of Gender Gaps in Labour Outcomes. Boulogne Billancourt: OECD Development Center.

Gidengil, Elisabeth, André Blais, Richard Nadeau, and Neil Nevitte. 2003. Women to the Left? Gender Differences in Political Beliefs and Policy Preferences. Women and Electoral Politics in Canada: 140-59.

di Giovanni, Julian and Andrei A. Levchenko. 2009. Trade Openness and Volatility. The Review of Economics and Statistics 91(3): 558-85.

Glass, Jennifer and Valerie Camarigg. 1992. Gender, Parenthood, and Job-Family Compatibility. American Journal of Sociology 98(1): 131-51.

Guisinger, Alexandra. 2009. Determining Trade Policy: Do Voters Hold Politicians Accountable? International Organization 63(3): 533-57.

Guisinger, Alexandra. 2016. Information, Gender, and Differences in Individual Preferences for Trade. Journal of Women, Politics \& Policy 37(4): 538-61.

Guisinger, Alexandra. 2017. American Opinion on Trade: Preferences without Politics. Oxford University Press.

Hall, H. Keith, Chihwa Kao, and Douglas Nelson. 1998. Women and Tariffs: Testing the Gender Gap Hypothesis in a Downs-Mayer Political-Economy Model. Economic Inquiry 36(2): 320-32.

Hall, Robert E., Aaron Gordon, and Charles Holt. 1972. Turnover in the Labor Force. Brookings Papers on Economic Activity 1972(3): 709-64.

Hiscox, Michael J. and Brian A. Burgoon. 2004. The Mysterious Case of Female Protectionism: Gender Bias in Attitudes toward International Trade. Harvard University Weatherhead Center for International Affairs. Disponible online: http://www.tinyurl.com/meb2eqm

Kleinberg, Katja B. and Benjamin O. Fordham. 2011. What We Don't Know (or Refuse to Say) About Gender and Trade Policy Preferences. In APSA 2011 Annual Meeting Paper.

Kose, M. Ayhan, Eswar S. Prasad, and Marco E. Terrones. 2006. How Do Trade and Financial Integration affect the Relationship between Growth and Volatility? Journal of International Economics 69(1): 176-202.

Kushi, Sidita and Ian P. McManus. 2018. Gendered Costs of Austerity: The Effects of Welfare Regime and Government Policies on Employment across the OECD, 2000-13. International Labour Review 157(4): $557-87$.

Lee, Hyunji. 2011. "The Source of Female Protectionism: The Consequence of the Knowledge Gap in Economics." Chapter 2. The Influence of Sociotropic Judgment on Public Perceptions of Trade Liberalization: Distributional Judgment and Institutional Factors, Ph.D. diss. The University of British Columbia.

Mansfield, Edward D., Diana C. Mutz, and Laura R. Silver. 2015. Men, Women, Trade, and Free Markets. International Studies Quarterly 59(2): 303-15.

Mayda, Anna Maria and Dani Rodrik. 2005. "Why Are Some People (and Countries) More Protectionist than Others? European Economic Review 49(6): 1393-430.

Padavic, Irene, Barbara F. Reskin et al. 2002. Women and Men at Work. Pine Forge Press.

Presser, Harriet B. 1994. Employment Schedules among Dual-Earner Spouses and The Division of Household Labor by Gender. American Sociological Review: 348-64.

Ramey, Garey and Valerie A. Ramey. 1994. Cross-Country Evidence on the Link between Volatility and Growth. Technical report. National Bureau of Economic Research. 
Sheeran, Timothy J. 1975. Title VII and Layoffs under The Last Hired, First Fired Seniority Rule: The Preservation of Equal Employment. Case Western Reserve Law Review 26: 409.

Tingley, Dustin, Teppei Yamamoto, Kentaro Hirose, Luke Keele, and Kosuke Imai. 2014. Mediation: R Package for Causal Mediation Analysis. Journal of Statistical Software 59(5).

Tomiura, Eiichi, Banri Ito, Hiroshi Mukunoki, and Ryuhei Wakasugi. 2016. Individual Characteristics, Behavioral Biases, and Trade Policy Preferences: Evidence from a Survey in Japan. Review of International Economics 24(5): 1081-95.

Ureta, Manuelita. 1992. The Importance of Lifetime Jobs in the US Economy, Revisited. The American Economic Review 82(1): 322-35.

Women's Budget Group. 2018. Exploring the Economic Impact of Brexit on Women. Technical report. https://wbg.org.uk/wp-content/uploads/2018/03/Economic-Impact-of-Brexit-on-women-briefing-FINALfor-print.pdf.

Cite this article: Brutger R. and Guisinger A (2022). Labor Market Volatility, Gender, and Trade Preferences. Journal of Experimental Political Science 9, 189-202. https://doi.org/10.1017/XPS.2021.9 